\title{
Biology and Religion.1
}

\author{
By Prof. J. S. Haldane, F.R.S.
}

FOR religion the world, whether visible or invisible, is the manifestation of God. The real basis of religion lies in our own conscious experience, in our awareness of values which determine the course of our existence and unite us all but cannot be regarded as derived from either individual or collective selfinterest. In so far as we realise these values, their objective reality, and their unity, we acknowledge, whether we are aware of it or not, that our universe is a spiritual universe and the manifestation of one God.

The theories of natural science seem to recognise neither objective ethical values nor God. Yet many scientific men have been deeply religious, and in one way or another have, even though often unsatisfactorily, reconciled their science with their religion. With the progress of science in recent times such reconciliation has seemed to become more and more difficult, and the existence of spiritual reality in the sense implied in religion has seemed to become more and more shadowy. During the nineteenth century this process was very marked ; and it was particularly the progress of biology, and only to a minor extent that of historical criticism, that brought the difficulty to a head. I shall endeavour in this paper to indicate what seems to me the cause of the difficulty, and to maintain at the same time that however uncompromising the attitude of biology is, and I hope always will be, towards obsolete details of theological creeds, there is in reality nothing to come between biological science and real religion.

Perhaps we can best realise the cause if we call to mind the argument of a once popular book, Paley's "Natural Religion." Paley argued that, first, the human or animal body is a piece of exquisitely perfect machinery; and that, secondly, the existence of this wonderful machinery is clear evidence of the existence of a superhuman Designer. His argument was not very original, but it was at any rate put with great clearness. The first step came to be accepted by the great majority of physiologists; but the second step was invalidated by the discovery of evolution and the theory of natural selection. It is, however, to the first step that I wish to direct attention; for the essence of the whole matter is there.

Granted that the body is a machine, Paley would have said that the soul is placed within to control its voluntary working. Nevertheless, the more the matter has been investigated the more clearly has the fact seemed to emerge that the conscious control of the machine is dependent on exactly the same sort of material conditions as its ordinary unconscious working. We need only, for example, reduce the oxygen supply, or cut off the supply of some substance supplied by a gland, to produce not only loss of normal conscious control, but also a condition akin to, or identical with idiocy. If, therefore, the body depends upon mechanical conditions, so also does the mind or soul. Moreover, moral and mental characters are just as clearly transmitted by ordinary generation as bodily characteristics. In Paley's time, and indeed for long afterwards, many

\footnotetext{
1 From a paper read at the Conference of Modern Churchmen, at Oxford, on August 28.
}

physiologists believed that there is active in the living body a factor which they called vital force, which is independent of the mechanical conditions. But the observations just quoted are fatal to vitalism also.

Paley's first step, taken in conjunction with the further development of physiology, thus leads us straight towards what is called materialism. Consciousness becomes a mere mysterious accompaniment of mechanical processes; and spiritual values have ultimately no more meaning than they can have in a purely physical world.

Paley was a product of his time. With his generation, and succeeding generations, he accepted the assumptions about the nature of visible physical reality which had come down to him from Galileo and Newton. 'These assumptions were that visible reality consists of selfexistent bodies separated from one another in selfexistent space and time, and acting on one another according to the definite laws of mechanics, physics and chemistry. The human body, as a part of visible reality, must be just as much subject to these laws as inorganic bodies.

But Newton's conclusions about visible reality were based on the observation of inorganic phenomena. They seem to fit these phenomena, or at least seemed until recently to fit them, though Newton himself was far from thinking that he had done more than make a beginning of applying them in detail. But do they fit the phenomena of life? If they do not, then Paley's first step was a false one, and the materialistic conclusions which have so naturally grown out of it fall to the ground. From the purely scientific point of view of biology itself, the question is fundamental. No one can doubt that the conception of a living organism as a mechanism such as Paley depicted is to a very large extent useful and convenient ; but is such a conception consistent with the characteristic phenomena of life and conscious behaviour? To this scientific question I have largely devoted myself since my student days.

If we observe the relation between physiological stimulus and response we find that, under standardised or "normal" conditions of environment, the response follows the stimulus as regularly as any physical effect follows its cause. But when the conditions of environment are altered, perhaps to only a very slight degree, this is no longer the case: the response is altered, perhaps totally prevented or "inhibited," to use a physiological term. The exact response of a limb, for example, to a stimulus, say a visual stimulus, acting on the body, depends on a host of stimuli varying in nature with the relative positions of the various parts of the body : depends also on endless other co-existent stimuli, whether visual or of other kinds. It is just the same with chemical stimuli acting on any part of the body whatsoever.

When we regard this phenomenon from a wider point of view, we see that we can with very considerable success predict what happens if we assume that the life of an organism is something which actively asserts and maintains itself, including the organism's relations to its environment, in a manner which is specific or "normal."

$$
\text { NO. } 2865 \text {, VOL. I I } 4]
$$


The responses and their modifications or inhibitions then fall into intelligible order. Apart from this assumption, characteristic physiological responses are nothing but unintelligible chaos : we cannot predict the characteristic manner in which stimuli and responses become associated and effective.

That the parts and activities of a living organism exist relatively to one another is evident. The very nomenclatures of biology presuppose this. Relativity reigns supreme in biology. But not only is this so: the relationships of life also actively assert and maintain themselves. The responses of the nervous system become intelligible from this point of view; but this is still more evident in connexion with the simpler responses within the body to molecular stimuli-the responses connected with respiratory exchange, assimilation and secretion. It is with these responses that my own experimental work has been mainly associated, and the study of them has left no doubt in my mind of the necessity for regarding the already defined conception of life itself as fundamental in biology.

Perhaps this necessity will become more easy to understand if I refer to the basis of practical medicine on its therapeutical side. When the organism is injured by any passing cause, tissues of exquisite delicacy have been destroyed or altered in structure. We have no means of repairing or replacing these structures as we might repair or replace the injured parts of a machine. Nevertheless, the injuries can be healed, and by various means we can facilitate the process or render it certain. It is because life actively maintains and reproduces its normals that recovery is brought about. What a doctor does is merely to aid Nature in the process. Any other view of the matter amounts to the mere quackery which has been repudiated by scientific medicine ever since the time of Hippocrates.

But I can almost hear some well-meaning scientific colleague saying "Your conception of life may be all very well as a sort of heuristic principle, but it is totally unintelligible. The process of healing and reproduction must depend on a series of molecular reactions ; and the right way to understand it is to investigate these reactions one by one. Since the living body is material it must be subject to the laws of all material action. In other words, it must be a mechanism, though a very finely balanced and complex molecular mechanism." Let us then suppose for the moment that this is so, and see how the assumption works out.

The living body reproduces itself from generation to generation. In the process of reproduction it grows from a microscopical speck, or rather two microscopical specks, the male and female elements, which have united to form one. Little or none of the assumed molecular machinery can exist in these specks : it must all be gradually built up again in the course of development. This development itself is a very complex process, which on the mechanistic theory would necessitate the existence of extraordinarily complex molecular machinery in the germinal specks, and corresponding machinery in the parent organisms for producing the germinal machinery. The mind recoils from the incredible complications involved.

Specific germinal cells in the bodies of animals can sometimes be followed in their successive divisions from one generation to another, and in this sense there is continuity of the germ-plasm. On the mechanistic theory, therefore, the molecular machinery of reproduction reproduces itself by fission from its like. But how is a delicate piece of machinery to reproduce itself by fission? Imagine the unspeakable confusion in such a process, or in the sexual union of two similar pieces of machinery!

I have perhaps said enough to show why I cannot regard the mechanistic theory of life as tenable. It involves quite impossible assumptions and leads us nowhere in respect of the characteristic phenomena of life. Not only the newspapers, but also scientific men, continue to speak of the mechanism of life and heredity : I confess that such an expression has no meaning whatsoever to me. We cannot dispense with the distinctive conception of life. Let there be no mistake, however, about what this implies. It implies that the old conception of visible reality which Galileo and Newton set forth has broken down; and that there is no use in appealing to that conception in support of a mechanistic theory of life. Life would be unintelligible on that conception; but it is reality that science has to deal with, and not an ideal world of mechanism. The ideal mechanical world of Galileo and Newton corresponds sufficiently well for most practical purposes with our experience of inorganic phenomena, but does not correspond with our experience of biological phenomena. The supposed self-existent bodies and separable reactions of the ideal mechanical world have turned out to be not really self-existent and separable; and we have to modify our fundamental conception of visible reality accordingly, though for many practical purposes the merely mechanical conception may suffice.

It may be many years before the significance of the phenomena of life for our conceptions of visible reality is generally understood; but assuredly this general understanding will in time be reached.

So far I have only discussed life in such a form as we seem to meet with in plants, or in the activities of parts of our own bódies which we assume to be unconscious. I now come to conscious activity. We know what conscious action is in ourselves, and we can easily infer its presence or apparent absence in other persons. We can also form some judgment as to its presence in even lowly organised animals.

Conscious is distinguished from unconscious experience or activity by the fact that a conscious experience or action carries with it an ordered reference to both past and anticipated experiences, as well as to other present experiences. It was Kant who first pointed out this fundamental fact clearly in relation to perception. A conscious experience not carrying in itself ordered relations to past and anticipated experience is a purely imaginary figment. This discovery constitutes the great advance which Kant made beyond Berkeley and Hume. We cannot derive our conceptions of the spatial and temporal orderliness of our world from separate experiences of it : the orderliness is already given in any experience, and belongs to it. An ordered universe existing apart from conscious experience of it would be nothing to us. It was to a world of relativity that Kant's analysis of perception led.

At first sight Kant's idealism seems to lead us into impossible or practically unmeaning conclusions ; but let us follow the same line of reasoning further than

NO. 2865 , VOL. I I 4$]$ 
Kant followed it. He belonged to his own time. The order which he found to be implied in conscious experience was simply the order of the physical world as pictured by Galileo and Newton; and indeed his idealistic philosophy became a sort of buttress to their ideas of visible reality. Whether visible reality was self-existent, or relative, or ideal did not seem to matter much in practice, although with relativity physics Kant's reasoning has now come in to prominence among physicists themselves.

When we examine our own conscious experiences and actions we find that they hang together in another manner besides those pointed out by Kant. They hang together or are essentially related in the manner already described in connexion with the phenomena of life. Whether we will or no, they influence and inhibit one another in a manner which cannot be predicted or understood on merely physical principles, and which only becomes more or less predictable or intelligible in the light of the conception of life. What Locke called the secondary qualities in experience come under this category, together with various natural appetites and instincts, repulsions and attractions. Into all our conscious perceptions and actions this element of relatedness enters, and not merely the relatedness in a physical sense, to which Kant directed attention. Both in connexion with ourselves and with other organisms is this true. It is only by a process of artificial abstraction that we can neglect the biological aspect of our conscious experience, and the neglect of this aspect has led to endless intellectual confusion.

We must not make the mistake of supposing that the conception of life stops short at the body-surface of an organism. A living organism cannot be separated in thought from its environment. In life the physiological relation to environment is maintained just as clearly as the physiological relation between the parts of the body. An organism belongs to its environment just as much as its parts belong to one another. Different individual organisms are also organically related to one another, by parenthood, sex relations, and mutual association of various kinds. The normal limits in duration of individual life are also an apparent evidence of this relationship.

In consciousness of the biological aspect of experience, and in corresponding conscious action, our lives have for us a past and future which is inseparable from the present. Our perceptions and actions are thus those of conscious interest, as distinguished from the blind immediacy of what we regard as mere biological phenomena. Our world is a world of interests and values, and our actions have a corresponding responsibility attached to them.

The existence of biological phenomena showed us that a mere mechanical conception of visible reality is fundamentally inadequate, however useful practically for some purposes. The progress of philosophical investigation since Descartes has also shown us that in whatever way we may for temporary practical purposes represent to ourselves the visible universe, it cannot be in reality anything but a universe of conscious existence. Berkeley, Hume, Kant, and their lineal successors have been in agreement about this, however short they may have stopped in the further development of their conclusion. Putting together this conclusion with the previous one, we find that our universe is a universe of perceived interests and values, and of responsible conduct.

Let us now examine further the nature of the interests and values which present themselves in perception and conscious behaviour. We can think of them in the first place as the interests of an individual human organism. In the life of a conscious organism, what is required for the maintenance of its normal organic life and structure is foreseen and provided for in the light of past experience, since conscious experience and action reach out, as Kant showed, into both the past and the future. In this process the environment is as much concerned as the body of the organism itself, since life, when we investigate it, involves, and indeed manifests itself in, a normal relation between living organic structure and environment. This fact is to some extent masked in higher organisms, which, as Claude Bernard first indicated, possess, in the form of their blood, an internal environment which by various means is kept amazingly constant in its character, and acts as a sort of buffer between the living tissues and the variations in the external environment; but now that physiologists have become aware of this, the true relations between organisms and environment are standing out ever more clearly. It is a relationship which can only be comprehended as an organic one : a merely physical interpretation of it is not possible. Even from the point of view of our merely individual lives, our environment is in no mere physical relationship to us : it is bone of our bone and flesh of our flesh.

An isolated individual human organism is, however, only a scientific abstraction: for without at least a mother or nurse no human infant could survive. In the perception more particularly of human relationships and corresponding actions, we become aware of wider interests than those centred round our individual organisms. The wider interests centre round family, countrymen, the human race, and extend also to animals, plants, and country. They extend also to both the past and future. In the experiencing of them it is just reality itself that is being revealed to us; and spiritual reality, not merely ideal scientific abstractions. We are, in fact, no mere self-centred beings, complete in ourselves; and those who set before themselves, and endeavour to act on, the idea that they are entirely self-centred are only doing violence to their own nature.

This latter conclusion seems to me equally clear even if we simply regard human behaviour from an abstract biological point of view. A higher organism is an assemblage of countless individual cells; but the behaviour of not one of them is intelligible biologically apart from its relations to the rest, and to the environment generally. In exactly the same way the biological behaviour of individual human organisms is unintelligible apart from their relations to other human organisms and the rest of their environment. Their very being in the biological sense manifests itself in this relationship. We belongl in the most intimate sense to our environment.

The wider interests which reveal themselves in human society have a compelling power which dominates what we regard as mere individual interests. In these wider interests we meet with something which we can in this sense describe as "not ourselves," though in another

$$
\text { NC. } 2 S 6: \text {, VOI.. I I : }]
$$


sense it is the reality of ourselves. It binds us together in spirit, so that what others feel and see we also feel and see. We thus attain to what we regard as objective perception, a perception that others share in, and that unites all men : also to corresponding objective standards of behaviour.

This perception and behaviour is not just the collective or average perception and behaviour of a number of individuals, but something which only shows itself in fellowship with others, and in the contemplation of our relationship with Nature. It is the manifestation of the spiritual Reality of our universe-the Reality which men call God.

We are so accustomed to regard reality as physical reality in the sense of Galileo and Newton that any more adequate conception of reality seems to us far away and unreal--mere mysticism. We are the children of a materialistic age. We look for a soul consisting, if not of ordinary matter in the mechanical sense, yet of something which is only a thinly veiled imitation of it. We look, also, for a similarly constituted God. Such entities can never be found. God is with us, in us, and everywhere around us, as Jesus taught. We must learn to see spiritual reality, and not the mere appearances of matter. We must learn, also, that the voice of God is not a voice threatening us from outside with material punishments or coaxing us with the hope of material rewards, but a voice which, when we hear it, transforms our most hidden motives and thoughts.

Let me return to the relations of biology and other branches of natural science to religion. Perhaps it might seem that what I have been saying attributes to natural science the responsibility of blinding us to spiritual reality. Are not, for example, Galileo and Newton, and the great biologists who have treated the living body as if it were a piece of mechanism, responsible in this respect? To point out that theologians are equally responsible does not answer this question. I wish to consider it directly.

When we examine the original contributions of great men of science we always find, first, that on the data before them their conclusions were justified, and, secondly, that these conclusions were calculated to be of great practical use to their fellow men. If it is true that the reality of our universe is spiritual, it is no less true that we are constantly struggling with illusion and imperfection, and that it is only in that struggle that spiritual reality manifests itself to us. We cannot separate faith from works. The motive of science has always been the discovery of what, in one way or another, will be of use ; and at every turn we make use of scientific discovery in practical affairs. It does not matter how limited in scope the discovery may be, we can always make use of it. To take examples, the discoveries by Kepler of the mechanism by which images are focussed on the retina, or by Harvey of a mechanical process by which blood is circulated through the body, were limited in scope, but of immense practical service. The eye cannot be regarded as a mere mechanical structure, nor the circulation as a mere mechanical process, so there is a reality beyond these discoveries. This does not, however, detract from their value, any more than the discoveries of Einstein have detracted from the value of Newton's discoveries.

Scientific investigation is just part of the struggle in which spiritual reality manifests itself ; and the realisation of this brings science, particularly pure science, very near to religion. It is only when science becomes dogmatic that it assumes an attitude which seems to deny the existence of spiritual reality. We find very little of this dogmatism in the writings of great men of science, but much more of it in the desiccated science of systematic text-books and popular expositions. For example, the idea is spread abroad in such writings that natural science, unlike philosophy, advances by a steady process of addition. We have only to look back on the history of natural science to see how utterly misleading this idea is. The progress of science is just as much strown with the remnants of discarded theories as is the progress of philosophy; but, in spite of this, continuity of development is evident in the histories of both of these subjects. Surely it must be the same with theology.

During most of my life I have been struggling more or less with scientific dogmatism, but I have never before addressed an audience mainly clerical. I wish to take the opportunity, therefore, of adding my voice to those of others who are engaged in struggling with the shackles of theological dogmatism. There are very many who, like myself, are kept away from existing churches by creeds and church services which they cannot honestly countenance, and perhaps a still larger number who are actively hostile because they regard churches as hotbeds of superstition. If I thought that my country could get on equally well without churches I should not care what was taught in them. But I do not think so. We need to be constantly reminded of that spiritual reality which manifests itself in willing service of every kind, and without the perception of which our country would relapse into chaos.

The churches cannot afford to be hampered by unintelligible beliefs which are mainly materialistic accretions of Christianity and greatly weaken its influence on those who are worth influencing. Religion itself stands on ground which cannot be assailed : it has no use for rickety defences. The story of Jesus and His teaching appeals to all men, and influences them practically, because it touches what is deepest and most real in them. Many, however, feel forced to conclude that that teaching was based only on emotional illusion. Hence adequate philosophical or theological support is needed for it. This support should be based on the widest philosophical and scientific knowledge. Any shirking of the questions involved, or cowardly sheltering behind mere traditional authority, is fatal. The true function of a church is to help men to see reality as a whole, and to guide their actions accordingly, thus preventing social chaos, intellectual confusion, and artistic decay.

You are members of the national Church of England, and we are meeting near the spot where one of the greatest leaders of that Church, a man of English yeoman stock, met his end. It is to Latimer that my mind goes back when I appeal for intellectual freedom in the English Church. He stood, not only for social justice and humanity in his country, but also for intellectual freedom. It was not of his own sufferings, or his own soul, that he spoke as he was dying, but of the England he had served so fearlessly, so lovingly, so faithfully, thus finding oneness with God.

The candle which was lighted in England as Latimer and Ridley perished is still burning.

No. 2865, VOI, I I 4 ] 